\title{
COMPARATIVE ANALYSIS OF PEAT FIBRE PROPERTIES AND PEAT FIBRE-BASED KNITS FLAMMABILITY
}

\author{
Daiva Mikucioniene1, Lina Cepukone1, Khalifah A. Salmeia², Sabyasachi Gaan² \\ ${ }^{1}$ Kaunas University of Technology, Faculty of Mechanical Engineering and Design, Kaunas, \\ Lithuania, Studentu str. 56, LT-51424 Kaunas, Lithuania, daiva.mikucioniene@ktu.It \\ ${ }^{2}$ Additives and Chemistry, Advanced Fibers, Empa, Swiss Federal Laboratories for Materials Science and Technology, \\ St. Gallen CH-9014, Switzerland
}

\begin{abstract}
:
A very promising cellulose-based natural fibre that is suitable for use in the textile industry is peat fibre. This fibre is a by-product of peat excavation, purified by separating it from other components. In this study, the morphological, chemical and mechanical properties of peat fibres as well as flammability of peat-based knitted fabrics were analysed. The average diameter of the peat fibres is $\sim 60 \mu \mathrm{m}$, but it varies in very wide ranges - 25-150 $\mu \mathrm{m}$; however, the number of fibres with diameter more than $100 \mu \mathrm{m}$ is very low. As the peat fibre contains a high amount of lignin, lignin amount in the mixed peat/cotton yarn is relatively high too. Lignin is responsible for enhanced flame retardancy; therefore, time to ignition of the peat knit is $\sim 30 \%$ higher than that of the cotton knit. Consequently, peat fibre can be used in the knitted structure in order to significantly reduce its flammability. In order to increase the flame retardancy, the knits have been treated by flame retardant in various concentrations. It was found that around the burned hole on the peat knit, treated by very low concentration flame retardant, forms charred area and the knit stops to burn even if the flame source is not removed.
\end{abstract}

\section{Keywords:}

peat fibre, cellulose, knitted structure, flammability, time to ignition.

\section{Introduction}

In the recent years, considerable attention has been paid to environmental issues. Processing in textile industry, in general, is one of the most environmentally damaging activity. In order to preserve the environment and to reduce waste, there is growing trend to use natural sustainable fibres and technologies that generate as low as possible waste. Natural fibres, such as cotton, are not necessarily greener than synthetic ones, because cotton requires an abundant amount of pesticides to grow. Organic silk, organic wool, soy silk, hemp, bamboo and nettle fibres are sustainable and can be replenished within a short time. They also take up less farmland than ordinary crops and require fewer chemicals to grow [1]. The global production of natural fibres is evaluated at the level of 35-40 million tons/ year. It is expected that the global megatrends in population growth, climate change and limited cotton supply will lead to a demand overhang for other cellulosic fibres, including new lately discovered natural fibres [2]. A very promising natural fibre is a peat fibre, constituent of the sheathed cotton grass sedge Eriophorum vaginatum. This fibre is a by-product of peat excavation operations. When peat is excavated from bogs, it must be purified by separating it from other components. One major component of the peat fibre is the cotton grass bast fibre formed when the plant dies and partly decomposes [3]. Peat is used in different fields of application, such as energy generation, agriculture, building materials, industrial and infrastructure development and medical purpose. About $90 \%$ of peat is used for energy production. Peat fibres have a potential for textile applications [4].
Peat properties reflect the peat-forming environment, development process of peat and the types of peat-forming plant. Peats are classified using the amounts of water-soluble substances, the cellulose and hemicellulose content, the lignin and lignin-derivatives and the nitrogenous constituents. These properties are used mainly to assess the potential of the peat material for industrial use. Organic components of peat can be divided into four groups. The first group is bitumen; the second group includes water-soluble matter, easily hydrolysed matter and cellulose; the third group is humus, which includes humic acid and fulvic acid; the fourth group is a kind of mixture including lignin, lignin-like matter and so on [5-7].

One major component of peat excavation waste, separated using a rotary screen, is the peat (cotton grass bast) fibre. Owing to the acidic and anaerobic nature of the bog, the stem and root of the plant do not decompose totally but deteriorate into the fibre. This fibre can be used in the textile industry [8]. In Central Europe, the peat fibre started to be used as a raw material for textiles at the end of 19th century. G.H. Beraud was the first who patent a process for the manufacture of peat yarn for the textile industry. In 1929, I. Wegman described the production of a fibrous material, whose spun could be suitable for textile. The peat fibres were to be extracted from the adhering peat and other not spinnable remainders of plants by mechanical machinery. The so extracted and cleansed fibre was not yet fit for spinning and for manufacturing valuable yarns. It has been found that a treatment with extracts from plants has a very good effect on the tensile strength, the appearance and the spinning properties of the peat fibre. 
Subsequently, after drying, the fibre was ready for spinning [9].

A number of physical and chemical properties can be deduced from what has been stated above regarding the development and composition of peat. Much of can be said with regards to peat also applies to the peat fibres, because these are a constituent of peat. The peat yarns can be developed by mixing it with wool, linen or cotton. The properties of peat still apply in such mixtures or increases the properties of the yarns with which it is spun [10].

Designing of a new fabric requires prediction of its behaviour before the manufacturing of the fabric. Therefore, investigation on the influence of various parameters on fabric properties and creation of a fabric design in accordance with its characteristics are very topical [11-16]. Flame retardancy is very important for materials from natural cellulosic fibre. Natural fibres are characterised by poor flammability characteristics, but their degree of resistance to fire is very different. It depends on the nature of the material, moisture content, density, fibre diversity elementary fibre thickness, chemical composition and fibre material orientation. Variation in the cellulose-based natural fibre flammability is in part due to differences in fibre microstructure and chemical composition. The chemical composition of cellulose-based fibres is dependent on their source (i.e., seed, leaf, cane, fruit, wood, bast and grass). Most natural fibres begin to degrade at temperatures exceeding 170-200 ${ }^{\circ} \mathrm{C}$. Cellulose, lignin and hemicellulose, the major fibre components, behave in different ways. The pyrolysis of hemicellulose occurs rapidly from 220 to $315^{\circ} \mathrm{C}$. Lignin is responsible for char formation, which protects the integrity of textile's surface by acting as a layer of fire insulation. Thus, increased char formation during the burning process is a good indication of flame retardancy. Lignin is the most difficult to decompose, as it has a low decomposition rate, whereas high content of cellulose can result in an increased flammability $[17,18]$. Flammability of natural fibres treated with a variety of flame retardants have been studied by many scientists [19-23]. But quite often it has a negative effect on the textile product's comfort or even may have allergenic effect. Thus, it is very important to select the most suitable treatment and relevant concentration of used flame retardant.
In this study, the morphological and chemical properties of peat fibre as well as flammability of peat-based knitted fabrics were analysed.

\section{Materials and methods}

Experimental knits were produced in the textile company JSC Vegateksa (Kaunas, Lithuania). Fabrics have been knitted in a single jersey knitting pattern on a circular $14 \mathrm{E}$ gauge, 3" cylinder diameter, one needle-bed knitting machine Matec Techno New (Italy). The fabrics were knitted of peat (35 $\mathrm{m}^{-1}$ twists, $\mathrm{Z}$ twist direction) and cotton (35 $\mathrm{m}^{-1}$ twists, $\mathrm{Z}$ twist direction) yarns as well as of their various combinations made by folding the single yarns. The yarns were ordered and purchased from Finland. Tensile characteristics of the peat and cotton yarns were presented in the article published by authors in [24]. The main structural characteristics of newly designed and investigated fabrics are presented in Table 1 (Notes: (i) Sample code means the raw composition of the yarns used for samples' knitting: $P$ is peat, $C$ is cotton yarn. Number before the character indicates how many single yarns were used in one knitted loop; (ii) The relative error of all measurements $\delta$ is less than $5 \%$ ).

Analysis of fibre surface and cross section was performed using an optical microscope, Nikon Eclipse E200 and digital camera Lumenera Infinity 1 (using 40x (for yarns) and 100x (for fibres) magnification with $0.001-\mathrm{mm}$ accuracy) as well as by scanning electron microscopy (SEM). The fibre surface was scanned and analysed using an SEM , Quanta 200 FEG (10 $\mathrm{kV}$, magnification ranges of the specimens: $1,000 \mathrm{x}$ and 5,000x).

Peat (cotton grass) fibres diameter was measured using an optical microscope Askania RML5, using 40x magnification, digital camera Nikon Coolpix 4500, and software Metric. A total of 100 measurements were performed in each of two directions of cotton grass that had fibre cross section (as those fibres have an elliptical form of cross section) to evaluate the diameter of this fibre. A total of 1,000 measurements were performed to evaluate the diameter of the cotton grass bast fibres. A large amount of measurements were performed as diameter of those fibres is very irregular.

Table 1. Characteristics of investigated knitted fabrics

\begin{tabular}{|c|c|c|c|c|c|c|c|}
\hline $\begin{array}{c}\text { Sample } \\
\text { code }\end{array}$ & $\begin{array}{l}\text { Yarn fibrous } \\
\text { composition } \\
\text { and total linear } \\
\text { density (tex) }\end{array}$ & $\begin{array}{c}\text { Percentage } \\
\text { composition } \\
(\%)\end{array}$ & $\begin{array}{l}\text { Wale } \\
\text { density } \\
\left(\mathrm{cm}^{-1}\right)\end{array}$ & $\begin{array}{c}\text { Course } \\
\text { density } \\
\left(\mathrm{cm}^{-1}\right)\end{array}$ & $\begin{array}{l}\text { Actual loop } \\
\text { length (mm) }\end{array}$ & $\begin{array}{c}\text { Mass per } \\
\text { unit area } \\
\left(\mathrm{g} \mathrm{m}^{-2}\right)\end{array}$ & $\begin{array}{l}\text { Tightness } \\
\text { factor } \\
\left(\text { tex } 1 / 2 \mathrm{~cm}^{-1}\right)\end{array}$ \\
\hline $4 \mathrm{P}$ & Peat, 240 & 100 & 4.0 & 4.5 & 11.4 & 492.48 & 1.36 \\
\hline $4 \mathrm{C}$ & Cotton, 236 & 100 & 3.8 & 4.4 & 11.3 & 444.38 & 1.36 \\
\hline $1 P+3 C$ & Peat + Cotton, 237 & $25+75$ & 3.9 & 4.3 & 11.5 & 445.31 & 1.34 \\
\hline $2 P+2 C$ & Peat + Cotton, 238 & $50+50$ & 3.9 & 4.3 & 11.5 & 448.68 & 1.34 \\
\hline $3 P+1 C$ & Peat + Cotton 239 & $75+25$ & 3.9 & 4.3 & 11.5 & 460.54 & 1.34 \\
\hline
\end{tabular}


Chemical constituents of the peat fibre were carried out by Latvian State Institute of Wood Chemistry (Riga, Latvia) according to the Klason method.

Tensile characteristics of the peat fibres were determined using Zwick/Roell (Germany) tensile testing machine. The distance between clamps was $20 \mathrm{~mm}$; the tensile speed was $50 \mathrm{~mm}$ $\mathrm{min}^{-1}$. The average values of tensile force and elongation were calculated from 50 elementary tests.

The flammability of the knits was investigated using the horizontal test method according to the standard DIN 50050$1: 1986$, which is applicable to all textile materials. In accordance with the procedure, a fabric specimen was clamped wrinkle free between two plates in a horizontal position. The horizontal flammability test was used, and the burning time from the start until the flame arises on the surface of knit was measured. The height of the flame was $4 \mathrm{~cm}$, and the distance between the flame source and fabrics investigated was $2 \mathrm{~cm}$. Average values of the tests were calculated from five measurements.

Flammability test was performed for untreated knitted fabrics as well as for $4 P$ (peat fibre) and $4 C$ (cotton fibre) fabrics treated (in various concentration) with phosphorus-based flame retardant Aflammit ${ }^{\circledR} \mathrm{KWB}$ (Thor $\mathrm{GmbH}$, Germany). Formulation of the treatment solution is given as follows: 250 $\mathrm{g} \mathrm{I}^{-1}$ of AFLAMMIT ${ }^{\circledR} \mathrm{KWB}$ (flame retardant) was diluted in cold water, $20 \mathrm{~g} \mathrm{l}^{-1}$ of melamine formaldehyde cross-linking agent QUECODUR DM 70 (Thor $\mathrm{GmbH}$, Germany) and $1 \mathrm{~g} \mathrm{l}^{-1}$ of non-ionic wetting agent KYOLOX BAT (Thor $\mathrm{GmbH}$, Germany) were also diluted and added to the bath. Finally, the catalyst 15 $\mathrm{g} \mathrm{l}^{-1}$ of $85 \%$ phosphorus acid (as well diluted with water) was added to the bath. As-received peat yarns were hydrophobic (natural fat from the fibres); knitted fabrics were washed at $90^{\circ} \mathrm{C}$ for $30 \mathrm{~min}$ with a $2 \%$ standard detergent before the flame-retardant treatment. This pre-treatment was performed to remove hydrophobic impurities from the fibres and ensure its uniform flame-retardant treatment. After treatment with Aflammit ${ }^{\circledR} \mathrm{KWB}$, knitted fabrics were padded, dried at $100^{\circ} \mathrm{C}$ (to residual moisture of $6-8 \%$ ) and, immediately after the drying, cured for $2 \mathrm{~min}$ at $170^{\circ} \mathrm{C}$. After this treatment, knitted fabrics were washed out to prevent acid damages. Flammability tests were performed for fabrics treated by above-described flameretardant treatment as well as for fabrics treated by consistently decreased concentration of the flame retardant: $1: 2,1: 4,1: 8$, $1: 16$ and $1: 32$.

Before the experiments, all specimens of fibres, yarns and knits were preconditioned in the standard atmosphere according to the standard LST EN ISO 139:2005.

\section{Results and Discussion}

\subsection{Peat fibres morphology and chemical composition}

Cotton grass stem and head are shown in Figure 1. Mechanical characteristics of cotton grass head fibres as well as of bast fibres were investigated. SEM images of cotton grass head fibre surface and its cross section are presented in Figure 1.

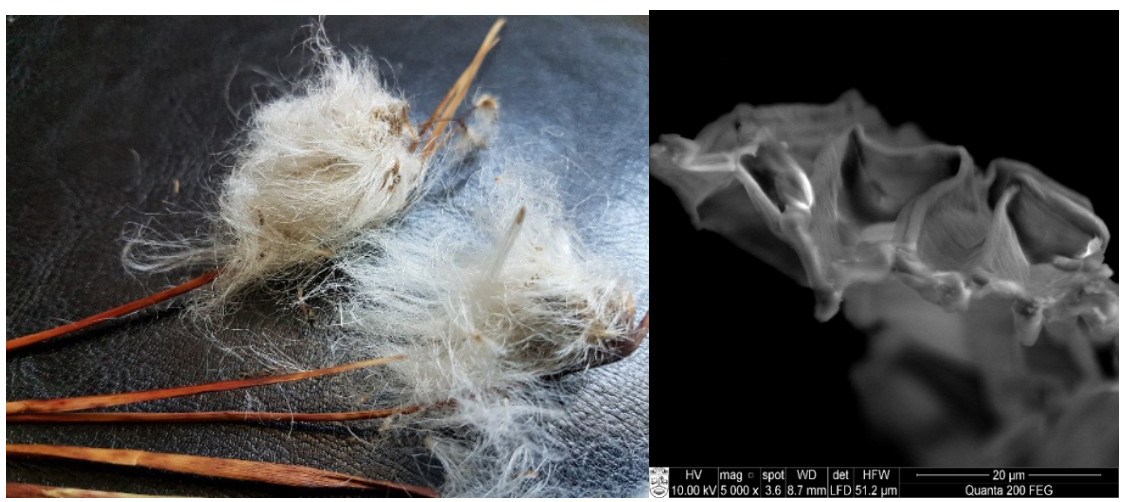

(a)

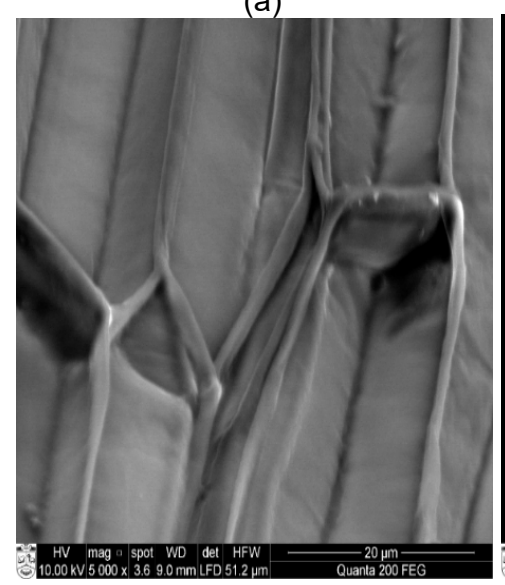

(b)

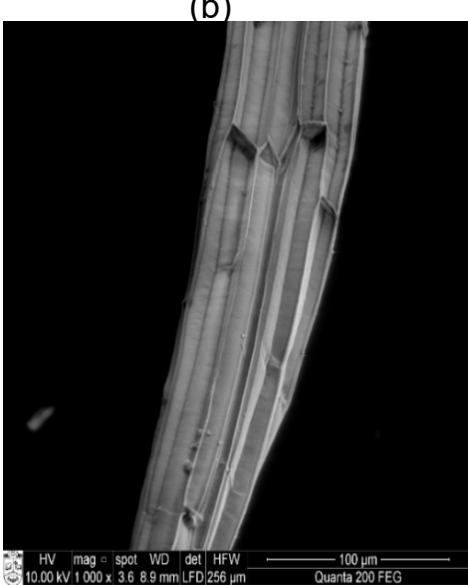

(c) (d)

Figure 1. Cotton grass (a) head fibre cross section (b), and longitudinal surface view (c), (d) (magnification rate for $(b)$ and $(c)$ is $5,000 \times$ and for (d) is $1,000 \times)$ 
As it can be seen in Figure 1 (a), the cross section of the cotton grass fibre has an elliptical shape (the average major diameter obtained by cotton grass head fibre is $81.96 \mu \mathrm{m}$, and the average minor diameter is $18.57 \mu \mathrm{m}$ ) as well as segmented and hollow structures. This segmentation is well visible in Figure 1 (b) and (c). Fibres of cotton grass head are not used for textile because of their weak mechanical characteristics. Owing to the segmented structure, breaking force of this fibre is only $1.08 \mathrm{cN}$. Also, it was noticed that this fibre is brittle. Thus cotton grass head fibres are not suitable for spinning.

Surface and cross-sectional view of cotton grass bast (peat) fibre that is used in peat yarns manufacturing is presented in Figure 2. Peat yarn, used in our knitted fabrics, is composed of two types of fibres - cotton and peat (cotton grass bast) fibres. The mass proportion of these fibres in the yarn is $40 \%$ of peat and $60 \%$ of cotton (longitudinal and cross-sectional view of the peat yarn is presented in Figure 3).

Structure of the peat fibre is quit compact; however, diameter varies, ranging from 25 up to $150 \mu \mathrm{m}$. Owing to such irregularity, the average fibre diameter was calculated based on 1,000 elementary measurements.

In Figure 4, the peat fibre diameter values and distribution which has character of a normal (Gaussian) distribution are presented. The average fibre diameter was $59.8 \mu \mathrm{m}$ (in comparison, average diameter of cotton fibres used in our knitted fabrics was $18.5 \mu \mathrm{m}$ ). The number of the thicker fibres, with diameter of more than $100 \mu \mathrm{m}$, is relatively low, only $2 \%$. This is because the thick fibres drop out during the spinning process. Owing to higher rigidity and higher diameter, the peat fibres are lost during the knitting process too. After knitting, proportional composition of the peat yarn changes, that is, the proportion of the fibres in the yarn is $25 \%$ of the peat fibres and $75 \%$ of the cotton fibres. Some more peat fibres can be lost during washing process. There were $20 \%$ of the peat fibres and $80 \%$ of the cotton fibres found in the machine washed and dried knitted fabric. Because of different properties of the peat and cotton fibres, knits made of pure cotton, pure peat and mixed peat/cotton yarns have different structural characteristics, such as loop length and geometry and tightness factor. [15].

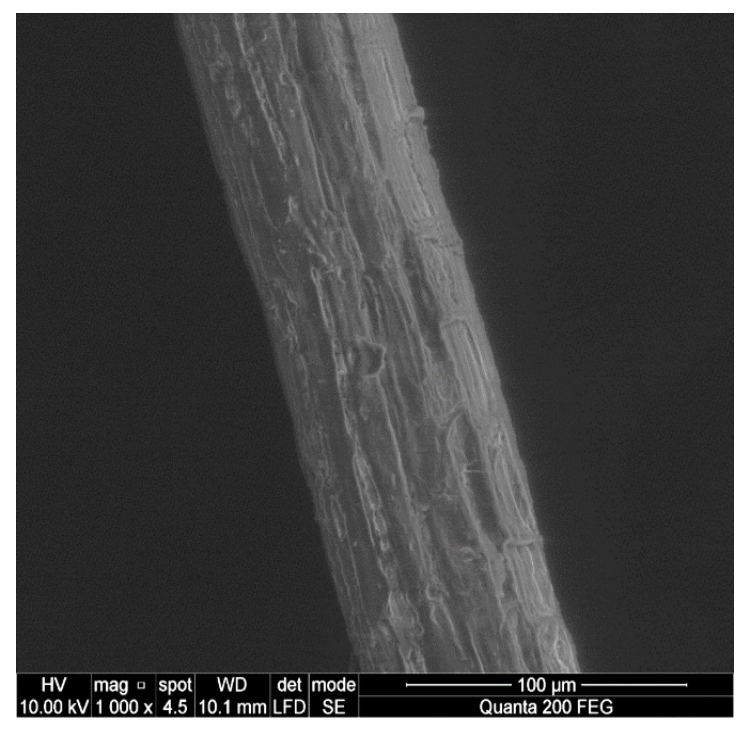

(a)

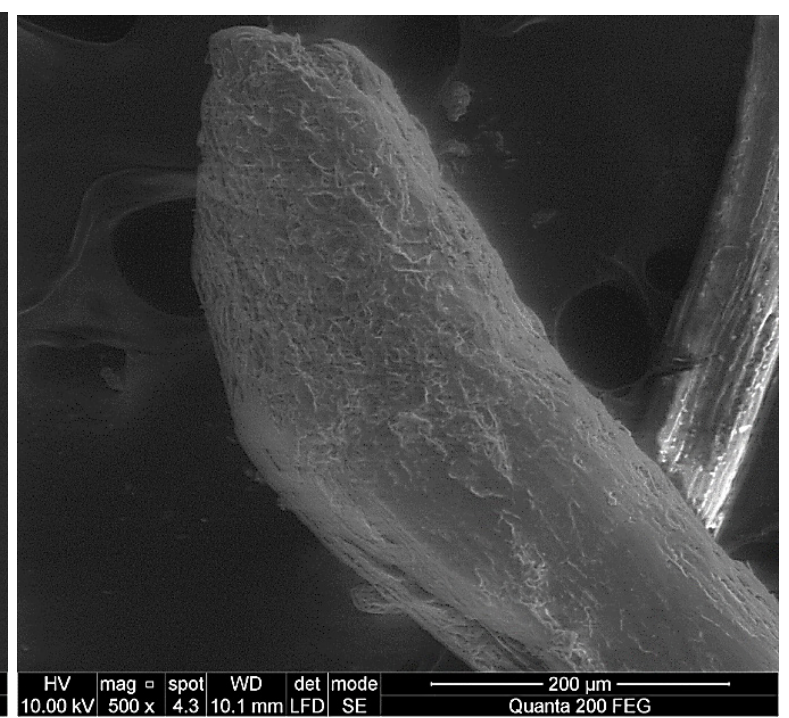

(b)

Figure 2. Peat fibre (cotton grass bast fibre): (a) longitudinal surface view and (b) cross-sectional vi ew

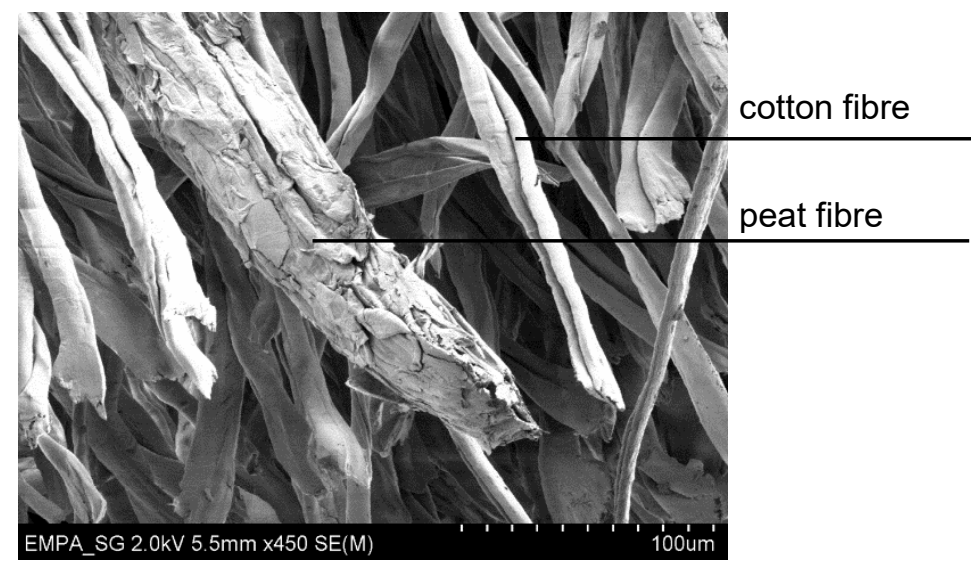

Figure 3. SEM image showing the peat yarn composition: two types of fibres - peat and cotton - are visible 
The chemical composition of the peat yarn used in this work are presented in Table 2. A raw cotton cellulose fibre is composed primarily of cellulose and impurities, such as wax (0.4-1.7\%), ash (inorganic salts; $0.7-1.8 \%)$, pectin $(0.4-1.9 \%)$ and others (resins, pigments and hemi-cellulose; 1.5-2.5\%) [25]. The majority of these impurities are removed during scouring and bleaching.

It is well known that lignin can influence combustion behaviour of cellulose-based textile. Lignin is the most difficult to decompose, as it has a low decomposition rate, whereas high content of cellulose can result in an increased flammability. The evident difference of lignin content in the cotton and the peat yarns creates presumption that burning of textile made of these yarns can behave in different way.

\subsection{Flammability}

Lignin is responsible for char formation on a textile's surface. Lignin, which is primarily composed of phenolic polymers, burns slowly, and during the burning process, it could produce aromatic chars. Biomass with higher lignin content has slower pyrolysis rates $[17,18]$. Char formation during the burning process is a good indication of flame retardancy. This char layer acts as fire insulation. In our previous investigations [18], the thermogravimetric analysis (TGA) of the cellulose and the peat yarns under nitrogen was carried out to understand their thermal decomposition. Depending on the chemical composition, these yarns exhibited different peak thermal decomposition temperatures (TdPeak) and percentage of residue at $800^{\circ} \mathrm{C}$. Samples of $100 \%$ cellulose showed the highest peak decomposition temperature of $366^{\circ} \mathrm{C}$. Owing to the presence of lignin and hemicellulose, a reduced TdPeak $\left(\sim 348^{\circ} \mathrm{C}\right)$ was observed for cotton grass fibres. A reduced TdPeak of $360^{\circ} \mathrm{C}$ was observed for peat yarn (unknitted from the fabric), which is due to its mixed composition (25:75 wt\%). The higher the TdPeak is, the more likely that flame will spread over the sample in the absence of any external source of flame or ignition. The residue at $800^{\circ} \mathrm{C}$ of burnt cotton fibres was $4.65 \%$, cotton grass fibres $15.57 \%$ and the peat yarn $13 \%$. The presence of lignin in cotton grass fibres increased the char formation.

In order to investigate the behaviour of knits during combustion and to find out the influence of peat fibre amount in the knitted fabric on the flammability, the horizontal burning test was carried out for fabrics, knitted of cotton and peat yarns as well as their various combinations. The results of the burning test are presented in Table 3 (sample codes are the same as in Table 1), and the combustion behaviour of knits with different fibre compositions is illustrated in Figure 5.

As from the results given in Table 3, the time to ignition of the peat yarn knits is $\sim 30 \%$ higher than that of the cotton knits. As it was discussed earlier, the peat knit contains more than 5 times higher amount of lignin than the cotton knit, and lignin is responsible for char formation during combustion as well as for fire insulation for a definite period. Flame arises on the

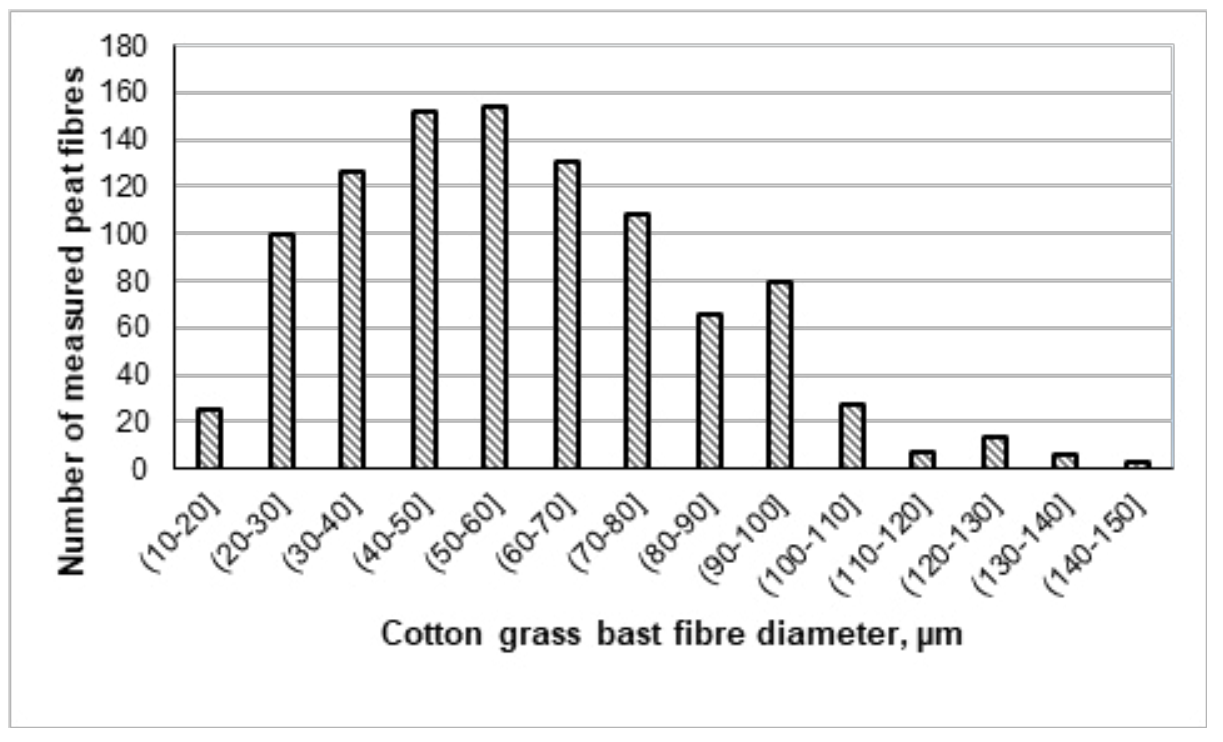

Figure 4. Distribution of cotton grass bast fibre diameter

Table 2. Chemical composition of the peat yarn

\begin{tabular}{|c|c|c|c|c|}
\hline & Cellulose (\%) & Hemicellulose (\%) & Lignin (\%) & Others (\%) \\
\hline Cotton fibre & 97.06 & 2.0 & 0.54 & 0.4 \\
\hline Peat fibre & 78.08 & 4.44 & 10.2 & 7.28 \\
\hline $\begin{array}{c}\text { Peat yarn } \\
\text { (peat 40 \% + cotton 60 \%) }\end{array}$ & 87.57 & 3.22 & 4.40 & 4.81 \\
\hline
\end{tabular}


surface of the cotton knit after $45 \mathrm{~s}$, whereas on the surface of the peat knit, only an area covered by char is visible after 45 $\mathrm{s}$ (see Figure 5) and flame arises on the surface of this knit after $64 \mathrm{~s}$, that is, $19 \mathrm{~s}$ later than that on the cotton knit. After few seconds, the peat knit stops to burn and the surface of the knit smoulders, forming a charred area. The cotton knit burns completely in more than $85 \mathrm{~s}$, whilst the peat knit smoulders still remains as a charred knitted structure. The presence of the peat fibres in the knitted structure increases time to ignition, and this increase correlates with the percentage of the peat fibres. A total of $25 \%$ of the peat yarns in the combined cotton/ peat knitted structure $(1 P+3 C$ variant $)$ increases the time to ignition to $\sim 7 \%, 50 \%$ of the peat yarns $(2 P+2 C$ variant) increases it to $\sim 22 \%$ and $75 \%$ of the peat yarns $(3 P+1 C$ variant) increases it to $\sim 29 \%$. Thus, the peat yarns, containing peat fibre with relatively high amount of lignin, can be used in the knitted structure to significantly reduce the flammability rate without additional chemical treatment by flame retardants.

However, the time to ignition of $1 \mathrm{~min}$ and less is insufficient to secure in the case of higher risk of fire. In order to enhance flame retardancy of cellulose-based textile used for protective clothing, finishing treatment by phosphorus-based flame retardant Aflammit ${ }^{\circledR} \mathrm{KWB}$ can be used. As producer of the flame retardant guaranty, flame retardancy of the peat and cotton knits, treated according to recommendations given in treatment instruction, is very high - the time to ignition of the peat knit is $17 \mathrm{~min} 15 \mathrm{~s}$ and that of the cotton knit is $19 \mathrm{~min} 40 \mathrm{~s}$ (see in Table 4). The time to ignition of the flame-retardant treated peat knit is more than 2 min lower than that of the cotton knit treated in the same conditions. The reason for this is the higher amount of lignin in the peat yarn. Nevertheless, both cotton and peat fabrics show very high flame retardancy.

After the treatment with the flame retardant Aflammit ${ }^{\circledR} \mathrm{KWB}$, the knitted fabrics become more rigid; therefore, it was decided to
Table 3. Time to ignition

\begin{tabular}{|c|c|}
\hline Sample code & Time to ignition (s) \\
\hline $4 P$ & 64 \\
\hline $4 C$ & 45 \\
\hline $1 P+3 C$ & 48 \\
\hline $2 P+2 C$ & 55 \\
\hline $3 P+1 C$ & 58 \\
\hline
\end{tabular}

Table 4. Burning time of knits treated with flame retardant

\begin{tabular}{|c|c|c|}
\hline \multirow{2}{*}{$\begin{array}{c}\text { Concentration of } \\
\text { flame retardant }\end{array}$} & $\begin{array}{c}|c| \\
\text { 4P (peat yarn } \\
\text { knit) }\end{array}$ & $\begin{array}{c}\text { 4C (cotton yarn } \\
\text { knit) }\end{array}$ \\
\hline $1: 1(\max )$ & $17 \min 15 \mathrm{~s}$ & $19 \min 40 \mathrm{~s}$ \\
\hline $1: 2$ & $12 \min 35 \mathrm{~s}$ & $14 \min 20 \mathrm{~s}$ \\
\hline $1: 4$ & $8 \min 45 \mathrm{~s}$ & $9 \min 25 \mathrm{~s}$ \\
\hline $1: 8$ & $6 \min 15 \mathrm{~s}$ & $8 \min 15 \mathrm{~s}$ \\
\hline $1: 16$ & $3 \min 30 \mathrm{~s}$ & $6 \min 35 \mathrm{~s}$ \\
\hline $1: 32$ & $1 \min 30 \mathrm{~s}$ & $3 \min 55 \mathrm{~s}$ \\
\hline
\end{tabular}

perform flame-retardant treatment using lower concentration of the flame retardant. The treatment was performed for the cotton and peat fabrics using 2, 4, 8, 16 and 32 times lower concentrations of Aflammit ${ }^{\circledR} \mathrm{KWB}$, and their time to ignition after each treatment was analysed. The results of ignition time investigation, using lower concentration flame retardant, are presented in Table 4, and the dependence of the knits flammability on the flame retardant concentration is presented in Figure 6.
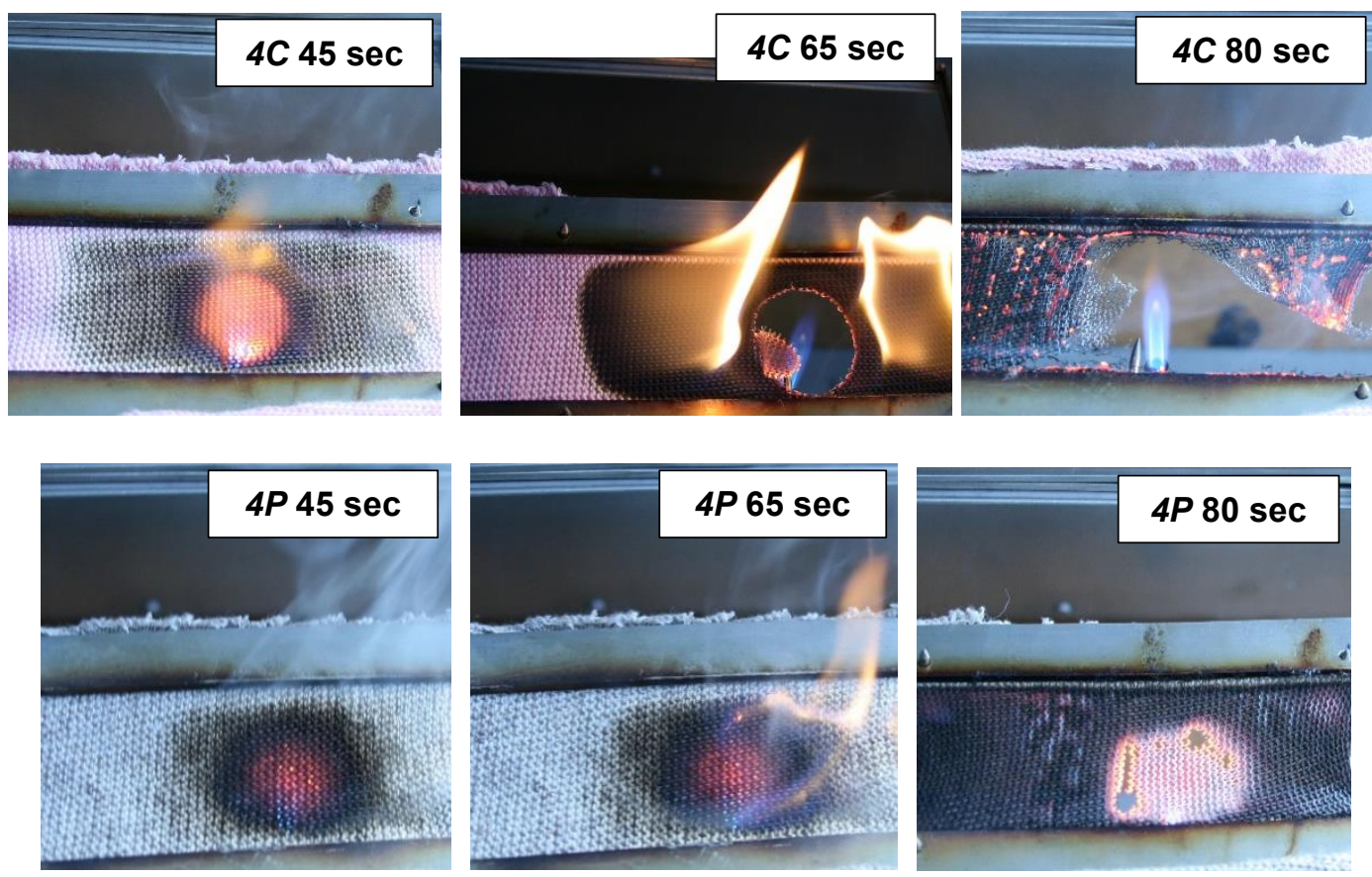

Figure 5. Combustion behaviour depending on the fibre composition of knits: $4 C, 100 \%$ cotton yarns; $4 P, 100 \%$ peat yarns 


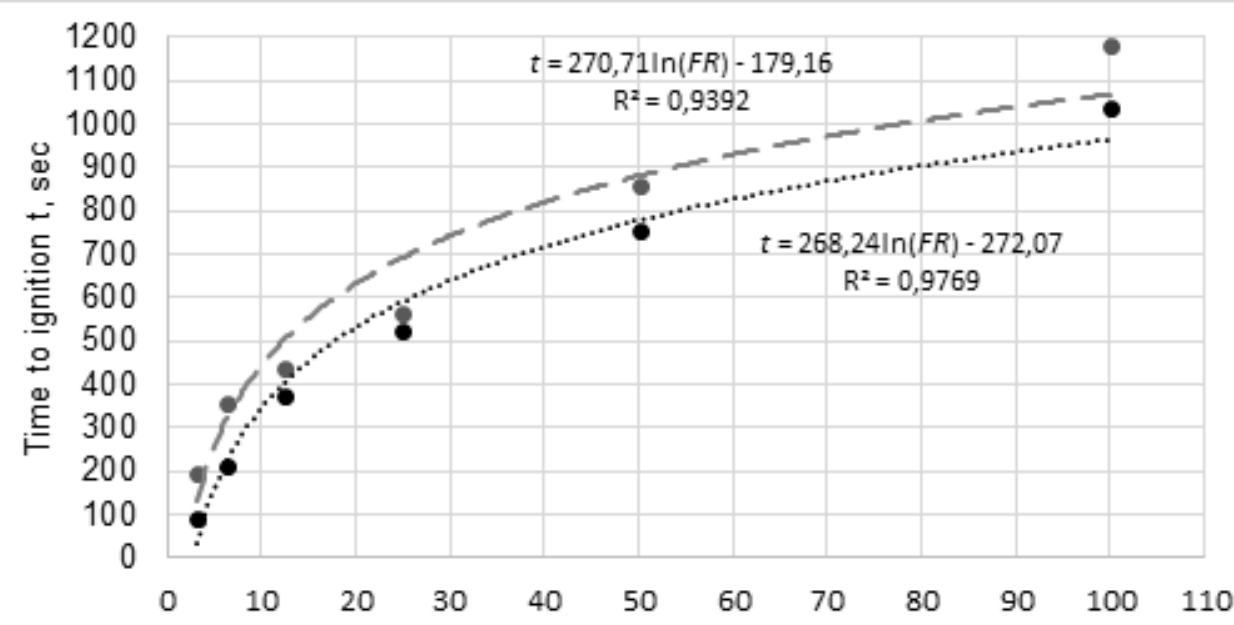

Flame retardant concentration FR, \%

- Peat knit - Cotton knit

Figure 6. Dependence of knits' ignition time on concentration of flame retardant Aflammit ${ }^{\circledR} \mathrm{KWB}$

Dependence of flammability on the concentration of the flame retardant Aflammit ${ }^{\circledR} \mathrm{KWB}$ can be well described by logarithmic equation (the coefficient of determination $(R 2)$ for cotton knits is 0.9392 and for peat knits is 0.9769 ). Character of the presented dependence illustrates that even very low concentration of the flame retardant gives an apparent increase in the ignition time. However, the higher the flame retardant's concentration is, the lower is the impact on the time to ignition. Treatment by flame retardant with two times lower concentration reduced burning time of both peat and cotton knits to $\sim 28 \%$, flame retardancy remains high though $-12 \min 35 \mathrm{~s}$ for the peat knit and 14 min $20 \mathrm{~s}$ for the cotton knit; meanwhile, the rigidity of the knits changes after such treatment insignificantly. Even using very low concentration of phosphorous-based flame retardant (32 times lower concentration than is recommended by producer), the time to ignition of the cotton knit is $\sim 4.5$ times higher than that of the untreated cotton knit. The time to ignition of the peat knit treated by flame retardant of such low concentration is only $\sim 1.5$ times higher than of the untreated peat knit; however, it is important that around the burned hole on the peat knit forms charred area and the knit stops to combust even if the flame source is not removed. This property is very significant for fire safety, as not only the time to ignition but also the time during which the flame extinguishes is important. If textile stops to combust without removing of the flame source, it can be characterised as textile with low flammability.

\section{Conclusions}

The cotton grass head fibres are not suitable for textile because of their weak mechanical characteristics (breaking force of this fibre is only $1.08 \mathrm{cN}$ ). The sustainable peat (cotton grass bast) fibre, which is obtained as waste product in peat excavation, can be used in the peat yarns manufacturing. The average diameter of the peat fibres is $\sim 60 \mu \mathrm{m}$, but it varies according to the normal (Gaussian) distribution in wide ranges - from 25 up to $150 \mu \mathrm{m}$. In comparison, the average diameter of the cotton fibres used was $18.5 \mu \mathrm{m}$. The number of fibres with diameter of more than $100 \mu \mathrm{m}$ is relatively low, only $2 \%$. The proportional composition of the peat yarn used in this research was $40 \%$ of peat and $60 \%$ of cotton fibres. Owing to higher rigidity, the peat fibres of higher diameter were lost during the knitting process and proportional composition of the peat yarn changed, that is, the proportion of the fibres in the knitted fabric was $25 \%$ of the peat fibre and $75 \%$ of the cotton fibre. Some more peat fibres can be lost during the washing process $-20 \%$ of cotton grass bast fibre and $80 \%$ of cotton fibre were found in the machine washed and dried fabric.

The chemical composition of the peat fibre is $78.08 \%$ cellulose, $4.44 \%$ hemicellulose, $10.2 \%$ lignin and $7.28 \%$ others (pectin, minerals, etc.). Accordingly, chemical composition of the peat yarn ( $40 \%$ of cotton grass bast $+60 \%$ of cotton fibres) is $87.57 \%$ cellulose, $3.22 \%$ hemicellulose, $4.40 \%$ lignin and $4.81 \%$ others.

As lignin is responsible for char formation on a textile's surface and this char layer acts as fire insulation, it was found that the presence of the peat fibre in the knitted structure reduces flammability of the knit. The time to ignition of the peat knit was $\sim 30 \%$ higher than that of the cotton knit $-64 \mathrm{~s}$ for the peat knit and $45 \mathrm{~s}$ for the cotton knit. Cotton knit burned completely in more than $85 \mathrm{~s}$, whilst the peat knit stops to burn after few seconds after ignition and smoulders until remains a charred knitted structure. It was noticed that around the burned hole on the peat knit surface forms the charred area and the knit stops to burn even if the flame source is not removed. The presence of the peat fibre in the knitted structure increased the time to ignition according to the percentage of the peat fibre, that is, $25 \%$ of the peat yarn in the combined cotton/peat knitted structure increased the time to ignition to $\sim 7 \%, 50 \%$ of the peat yarn increased it to $\sim 22 \%$ and $75 \%$ of the peat yarn increased it to $\sim 29 \%$.

In order to increase the flame retardancy, the peat and cotton knits were treated by phosphorus-based flame retardant Aflammit ${ }^{\circledR} \mathrm{KWB}$ at various concentrations. The time to ignition of 
the knits treated according to recommendations of the chemical manufacturer is very high $-17 \min 15 \mathrm{~s}$ for the peat knit and 19 $\min 40 \mathrm{~s}$ for the cotton knit; however, rigidity of the knits after such treatment increases. The time to ignition of both the peat and the cotton knits treated by flame retardant in two times lower concentration still remains high $-12 \mathrm{~min} 35 \mathrm{~s}$ for the peat knit and $14 \min 20 \mathrm{~s}$ for the cotton knit; meanwhile, the rigidity of the knits is changed after such treatments insignificantly. Dependence of the knits flammability on the concentration of the flame retardant has logarithmic character (the coefficient of determination (R2) for cotton knits is 0.9392 and for peat knits is 0.9769 ) and illustrates that even very low concentration of the flame retardant gives an apparent increase in the ignition time but do not have any influence on handle of the knit.

\section{References}

[1] Curteza, A. (2014) The sustainable fashion, a sensitive and complex approach from philosophy to research and innovation. 7th International Textile, Clothing \& Design Conference - Magic World of Textiles, October 5-8, 2014,17-28.

[2] Kozlowski, R., Mackiewicz-Talarczyk, M., Muzyczek, M., et al. (2016) Quo vadis Natural Fibers in 21st Century? Molecular Crystals and Liquid Crystals, 627(1), 198-209.

[3] World energy. https://www.worldenergy.org/data/ resources/country/sweden/peat/ (accessed 10 December 2017).

[4] Suoninen, A. (1976) New ideas and technologies in utilization of peatlands and peat in industry. In: Proceedings of the 5th international peat congress, Poznan, Poland, 21-25 September 1976. International Peat Society.

[5] Kivinen, E. (1980) Proposal for general classification of virgin peat. Proceedings of the 6th International Peat Congress, Duluth, 47-51.

[6] Paivanen, J. (1984) Peatland Forestry. Proceedings of the 7th International Peat Congress, Dublin, 4: 455-465.

[7] Schwerdtfeger, G. (1980) Comparison of peatlandclassification in different national systems of soil science. Proceedings of the 6th International Peat Congress, Duluth, 93-95.

[8] Suni, S., Kosunen, A.L., Hautala, M., et al. (2004) Use of a by-product of peat excavation, cotton grass fibre, as a sorbent for oil-spills. Marine Pollution Bulletin, 49, $916-$ 921.

[9] Wegman, I. Sertification: Process of Manufacturing a Textile Fibre from Peat. 1929.

[10] Fritz, E. (1995) The Curent Importance of Peat Textiles. Journal of Anthroposophical Medicine, 12(4), 1-4.

[11] Mikucioniene, D., Milasiute, L., Baltusnikaite, J., Milasius $R$. (2012) Influence of Plain Knits Structure on Flammability and Air Permeability. Fibres\&Textiles in Eastern Europe, 20(5), 66-69.
[12] Tvarijonaviciene, B., Mikucioniene, d., Ciukas, R. (2005) Influence of knitting process conditions and washing on tensile characteristics of knitted ribbon yarns. Fibres\&Textiles in Eastern Europe, 13(4), 74-77.

[13] Matusiak, M. (2017) Influence of the structural parameters of woven fabrics on their drapability. Fibres \& Textiles in Eastern Europe, 121(1), 56-64.

[14] Nadzeikiene, J., Milasius, R., Deikus, J., et al. (2006) Evaluating thermal insulation properties of garment packet air interlayer. Fibres\&Textiles in Eastern Europe, 14(1), 5255.

[15] Mikucioniene, D., Cepukone, L. (2017) Comparative analysis of knits from peat fibre and its combination with other natural fibres. Fibres\&Textiles in Eastern Europe, 22(5), 24-29.

[16] Mikucioniene, D., Milasiute, L., Milasius, R. (2014) Influence of knits structure on flammability and comfortability. Autex Research Journal, 14(4), 226-232.

[17] Dorez, G., Ferry, L., Sonnier, R., et.al. (2014) Effect of cellulose, hemicellulose and lignin contents on pyrolysis and combustion of natural fibers. J Anal Appl Pyrolysis, 107, 323-331.

[18] Salmeia, K.A., Jovic, M., Ragaisiene, A., et al. (2016) Flammability of cellulose-based fibers and the effect of structure of phosphorus compounds on their flame retardancy. Polymers, 8(8), 293; doi:10.3390/ polym 8080293.

[19] Lazko, J., Landercy, N., Laoutid, F., et al. (2013) Flame retardant treatments of insulating agro-materials from flax short fibres. Polymer degradation and stability, 98(5), 1043-1051.

[20] Freivalde, L., Kukle, S., Andžs, M., et al. (2014) Flammability of raw insulation materials made of hemp. Composites Part B: Engineering, 67, 510-514.

[21]Dorez, G., Taguet, A., Ferry, .L, Lopez-Cuesta, J.M. (2012) Thermal and fire behavior of natural fibers/PBS biocomposites. Polym Degrad Stabil, 98, 87-95.

[22] Salmeia, K.A., Gaan, S., Malucelli, G. (2016) Recent Advances for Flame Retardancy of Textiles Based on Phosphorus Chemistry. Polymers, 8(9), 319; doi:10.3390/ polym8090319.

[23] Afzal, A., Ahmad, S., Rasheed, A., et al. (2017) Influence of fabric parameters on thermal comfort performance of double layer knitted interlock fabrics. Autex Research Journal, 17(1), 20-26.

[24] Mikucioniene, D., Cepukone, L., Milasiene, D. (2018) Investigation on Mechanical and Thermal Properties of Knits from Peat Fibres and their Combination with other Natural Fibres. Textile Research Journal, 88 (14), 16601670.

[25] Gallo, J.M., Almirall, J.R. (2009) Elemental analysis of white cotton fiber evidence using solution ICP-MS and laser ablation ICP-MS (LA-ICP-MS). Forensic Sci Int, 190, 52-57. 